\title{
Alcohol consumption, substance use, and depression in relation to HIV Pre-Exposure Prophylaxis (PrEP) nonadherence among gay, bisexual, and other men-who-have- sex-with-men
}

Paul A. Shuper ${ }^{1,2^{*}}$ (D) Narges Joharchi ${ }^{1}$, Isaac I. Bogoch ${ }^{3,4}$, Mona Loutfy ${ }^{4,5,6}$, Frederic Crouzat ${ }^{6}$, Philippe El-Helou ${ }^{7}$, David C. Knox ${ }^{6,8}$, Kevin Woodward ${ }^{7}$ and Jürgen Rehm ${ }^{1,2,9,10,11,12,13,14}$

\begin{abstract}
Background: Although HIV pre-exposure prophylaxis (PrEP) substantially diminishes the likelihood of HIV acquisition, poor adherence can decrease the HIV-protective benefits of PrEP. The present investigation sought to identify the extent to which alcohol consumption, substance use, and depression were linked to PrEP nonadherence among gay, bisexual, and other men-who-have-sex-with-men (gbMSM).

Methods: gbMSM (age $\geq 18$, prescribed PrEP for $\geq 3$ months) were recruited from two clinics in Toronto, Canada for an e-survey assessing demographics; PrEP nonadherence (4-day PrEP-focused ACTG assessment); hazardous and harmful alcohol use (AUDIT scores of 8-15 and 16+, respectively); moderate/high risk substance use (NIDA M-ASSI ST scores $>4$ ); depression (CESD-10 scores $\geq 10$ ); and other PrEP-relevant factors. The primary outcome, PrEP nonadherence, entailed missing one or more PrEP doses over the past 4 days. A linear-by-linear test of association assessed whether increasing severity of alcohol use (i.e., based on AUDIT categories) was linked to a greater occurrence of PrEP nonadherence. Univariate logistic regression was employed to determine factors associated with PrEP nonadherence, and factors demonstrating univariate associations at the $p<.10$ significance level were included in a multivariate logistic regression model. Additive and interactive effects involving key significant factors were assessed through logistic regression to evaluate potential syndemic-focused associations.

\footnotetext{
*Correspondence: paul.shuper@camh.ca

${ }^{1}$ Institute for Mental Health Policy Research \& Campbell Family Mental Health

Research Institute, Centre for Addiction and Mental Health (CAMH), 33

Russell St., Toronto, ON M5S 2S1, Canada

2Dalla Lana School of Public Health, University of Toronto, 155 College St.,

Toronto, ON M5T 3M7, Canada

Full list of author information is available at the end of the article
}

(c) The Author(s). 2020 Open Access This article is licensed under a Creative Commons Attribution 4.0 International License, which permits use, sharing, adaptation, distribution and reproduction in any medium or format, as long as you give appropriate credit to the original author(s) and the source, provide a link to the Creative Commons licence, and indicate if changes were made. The images or other third party material in this article are included in the article's Creative Commons licence, unless indicated otherwise in a credit line to the material. If material is not included in the article's Creative Commons licence and your intended use is not permitted by statutory regulation or exceeds the permitted use, you will need to obtain permission directly from the copyright holder. To view a copy of this licence, visit http://creativecommons.org/licenses/by/4.0/ The Creative Commons Public Domain Dedication waiver (http://creativecommons.org/publicdomain/zero/1.0/) applies to the data made available in this article, unless otherwise stated in a credit line to the data. 


\begin{abstract}
(Continued from previous page)
Results: A total of 141 gbMSM (Mean age $=37.9$, white $=63.1 \%$ ) completed the e-survey. Hazardous/harmful drinking (31.9\%), moderate/high risk substance use (43.3\%), and depression (23.7\%) were common; and one in five participants (19.9\%) reported PrEP nonadherence. Increasing alcohol use level was significantly associated with a greater likelihood of nonadherence (i.e., 15.6, 25.0, and 44.4\% of low-risk, hazardous, and harmful drinkers reported nonadherence, respectively $\left.\left(X^{2}(1)=4.79, p=.029\right)\right)$. Multivariate logistic regression demonstrated that harmful alcohol use $(\mathrm{AOR}=6.72,95 \% \mathrm{Cl}=1.49-30.33, p=.013)$ and moderate/high risk cocaine use $(\mathrm{AOR}=3.11,95 \% \mathrm{Cl}=$ $1.01-9.59, p=.049)$ independently predicted nonadherence. Furthermore, an additive association emerged, wherein the likelihood of PrEP nonadherence was highest among those who were hazardous/harmful drinkers and moderate/high risk cocaine users $(\mathrm{OR}=2.25,95 \% \mathrm{Cl}=1.19-4.25, p=.013)$. Depression was not associated with nonadherence.

Conclusions: Findings highlight the need to integrate alcohol- and substance-focused initiatives into PrEP care for gbMSM. Such initiatives, in turn, may help improve PrEP adherence and reduce the potential for HIV acquisition among this group.
\end{abstract}

Keywords: HIV pre-exposure prophylaxis (PrEP), MSM, Adherence, Alcohol, Substance use, Depression

\section{Background}

Human immunodeficiency virus (HIV) persists as a public health issue, and within this context, gay, bisexual, and other men who have sex with men (gbMSM) continue to be disproportionately impacted by the virus compared to the population in general [1-3]. Of particular concern is that the decline in overall HIV incidence in countries such as the United States and Canada has not been reflected in corresponding populations of gbMSM, among whom HIV incidence has remained steady, and in some cases, has even increased [1-3].

In recent years, biomedical strategies have moved to the forefront of HIV prevention, with HIV pre-exposure prophylaxis (PrEP) - entailing a daily dose of tenofovir disoproxil fumarate/emtricitabine (TDF/FTC) or tenofovir alafenamide/emtricitabine (TAF/FTC) - offering noninfected individuals an effective method of protection from the virus. Empirical support for PrEP has been strong, with evidence from randomized controlled trials (RCTs) and real-world demonstration studies showing a reduction in the rate of HIV infection by $44-99 \%$ [410]. While this suggests that implementing PrEP on a broad scale could meaningfully reduce incident HIV among populations of gbMSM, PrEP's ability to prevent HIV has been shown to be directly contingent upon adherence. In fact, across a number of PrEP-focused RCTs that reported ranges of adherence from 29 to $98 \%$, the failure to adhere to PrEP was recognized as the most substantial hindrance to its effectiveness [11]. For example, in a seminal PrEP trial [5], PrEP-prescribed participants with non-detectable medication levels in their system were 13 times more likely to become infected with HIV than those with detectable levels; indicating that poor adherence diminished PrEP's HIV preventive effect (see also [7, 8, 12-14]). While some evidence suggests that on-demand PrEP (i.e., taking PrEP only in conjunction with sexual events) or intermittent PrEP (i.e., less frequent, non-daily dosing schedules) may provide a fair degree of protection $[7,9,12,15]$, given the marked adherence-related outcomes demonstrated across multiple PrEP RCTs, and recognizing some of the potential complexities surrounding non-daily PrEP dosing [16-19], PrEP guidelines have tended to maintain their impetus for daily PrEP adherence [20, 21].

\section{Alcohol consumption and adherence to PrEP}

Compared to the general population, alcohol-related issues have been shown to be disproportionately elevated among populations of gbMSM [22-25] as well as individuals who have been prescribed PrEP [26, 27]. Notably, such issues may be particularly detrimental to adherence. It has been theorized that consuming alcohol can limit the cognitive capacity required to remember to follow one's regimen as prescribed [28, 29], and in accord with this supposition, alcohol has repeatedly been associated with poor medication adherence [30], with much of this evidence derived from investigations on adherence to antiretroviral therapy (ART) among gbMSM living with HIV [29, 31]. More recently, a small number of studies have investigated alcohol's association specifically with adherence to PrEP; however, findings from this work have been mixed. Haberer et al. [32] found that individuals exhibiting heavy drinking patterns as identified through the validated Rapid Alcohol Problems Screen [33] were approximately three times more likely to be suboptimally adherent to PrEP (i.e., < $80 \%$ adherent based on unannounced pill counts) than those who did not consume alcohol at heavy levels. Similarly, Mugo et al. [34] reported that having sex "while drunk" was shown to be marginally associated $(p=.06)$ with lower 
adherence to one's PrEP daily dosing regimen (assessed as a continuous measure via medication event monitoring system). These patterns have been further supported through qualitative research, in which alcohol consumption was perceived to hinder one's ability to take PrEP as prescribed [35]. Diverging from these findings are those from Grove et al. [36], who found no link between heavy drinking during the past 30 days (i.e., $\geq 5$ drinks in one sitting) and self-reported PrEP adherence among a sample of gbMSM (half of whom were club drug users); and from Hojilla et al. [37], who found that recent binge drinking (i.e. $\geq 5$ drinks in a single day) was not significantly related to PrEP adherence as defined by dried blood spot tenofovir diphosphate concentrations. Of further divergence are the results from Velloza et al. [38], who demonstrated that compared to non-heavy drinking PrEP-users, those who reported heavy alcohol use (i.e., Alcohol Use Disorders Identification Test (AUDIT) score $\geq 8$ ) had significantly higher hair, but not plasma, FTC/TFV concentrations. The authors, however, indicated that this elevated concentration may have been due to a pharmacokinetic effect of alcohol on FTC/TFV levels.

Potentially contributing to the complexity of the alcohol and PrEP nonadherence relationship is the high prevalence of concurrent substance use and depression among gbMSM. A recent investigation quantifying the extent of such comorbidities demonstrated that almost $40 \%$ of hazardous drinking gbMSM had been diagnosed with a substance use disorder (i.e., other than alcohol), and over a quarter had been diagnosed with a major depressive disorder [39] (see also [40]). Within the context of PrEP treatment, substance use and depression on their own have been linked to PrEP nonadherence, but similar to alcohol, disparate findings have been yielded. Specifically, nonadherence has been significantly associated with the use of some types or classes of substances (e.g., stimulants, club drugs) but not others (e.g., cannabis) [36, 37, 41-44]; and the presence of depressive symptomatology has been associated with both an increased and decreased likelihood of PrEP nonadherence among gbMSM [45].

Taken as a whole, it remains unclear whether inconsistent findings involving alcohol, substance use, and depression derive from the possible underlying confounding of these concurrent factors. Despite the prominent use of "syndemic" approaches in the ART literature that have examined the synergistic interplay of substance use- and mental health-related issues in relation to ART nonadherence [46, 47], such methodologies have typically been absent from the PrEP literature; thus limiting our knowledge about the extent to which alcohol, either alone or in combination with comorbid substance use and/or depression, is linked to missing one's
PrEP doses. The present investigation therefore employed an encompassing approach aimed at 1) evaluating alcohol's possible independent association with PrEP nonadherence, and 2) exploring potential deleterious additive and interactive influences of alcohol in combination with concurrent substance use and depression on adherence behavior.

\section{Methods}

Participants, setting, and procedures

From August 2018 to February 2019, convenience sampling was employed to recruit participants from two clinics in downtown Toronto, Canada: one situated within a tertiary hospital and the other a stand-alone primary care community practice, that specialized in gbMSM- and HIV-focused medical services. Study eligibility criteria included: 1 ) $\geq 18$ years of age; 2) receiving daily PrEP from one of the two clinics; 3) taking PrEP for at least 3 months; and 4) identifying as gay, bisexual, and/or as a man who has sex with other men. Our target sample size was 120 out of a population of approximately 650 potentially eligible individuals across the two clinics. Clinic staff referred men who were presenting for PrEP-related care to an on-site Research Assistant who described the study and obtained written consent. Participants completed a confidential, self-administered e-survey that assessed PrEP adherence and its potential correlates (see "Measures" below). The e-survey was programmed using Qualtrics [48] and was designed to be completed within $30 \mathrm{~min}$. Participants received CAD \$30 ( USD \$22.50) for taking part in the study. All procedures were approved by Research Ethics Boards at the Center for Addiction and Mental Health (Protocol\# 101-2018) and the University Health Network (Protocol\# 18-5014).

\section{Measures \\ Demographics}

Items in the first section of the e-survey assessed age, race/ethnicity, level of education, and employment status. Participants were also asked about their current living situation and whether or not they presently had a steady partner.

\section{PrEP adherence and duration on PrEP}

The AIDS Clinical Trials Group (ACTG) 4-day adherence assessment [49] was adapted for the present investigation to measure adherence to one's PrEP regimen. Participants were asked to indicate whether or not they had missed their PrEP dose during each of the past 4 days. Nonadherence was defined as missing one or more PrEP doses during that timeframe. Duration on PrEP, in months, was asked through a single self-report item. 


\section{Alcohol use}

Consumption of alcohol during the past 12 months was assessed through the Alcohol Use Disorders Identification Test (AUDIT) [50]. The first item of the AUDIT, stating "How often do you have a drink containing alcohol?", was used to classify participants as non-drinkers versus drinkers (i.e., "never" vs. all other responses, respectively). Scores based on the full 10-item measure were categorized in accordance with AUDIT-based criteria to classify participants' consumption as "low risk" (scores 0-7), "hazardous" (scores 8-15), or "harmful" (scores $\geq 16$ ) [50].

\section{Substance use}

The National Institute on Drug Abuse Modified Alcohol, Smoking and Substance Involvement Screening Test (NIDA M-ASSIST) [51] was employed to classify substance use. Substances that were queried included cannabis, cocaine, stimulants, methamphetamines, inhalants, sedatives, hallucinogens, street opioids, and prescription opioids. For each substance, NIDA M-ASSI ST "substance involvement scores" were calculated to identify "Moderate-Risk" (scores 4-26) and "High-Risk" (scores 27+) use; reflecting consumption-related patterns and/or consequences that would warrant intervention. As only a very small number of participants met criteria for high-risk use (i.e., $n=3$ out of $N=141$ ), moderateand high-risk classifications were aggregated for each substance and categorized accordingly.

\section{Depression}

The self-report Center for Epidemiologic Studies Depression 10-item scale (CESD-10) [52] was employed to assess depressive symptomatology, and participants with a CESD-10 score $\geq 10$ were classified as depressed. A separate, single-item question designed for this study asked participants if they had received any treatment for depression (e.g., medication, counselling, psychotherapy) within the past 3 months.

\section{Sexual behavior}

A comprehensive assessment based on a validated, gbMSM-focused sexual behavior questionnaire [53] was adapted for this investigation. Participants were asked to indicate the number of HIV-negative, HIV status unknown, and HIV-positive partners (who were also delineated by perceived HIV viral load) with whom they had sex during the past 3 months. For each partner HIV serostatus category, participants were asked about the number of condom-protected and condomless receptive and insertive anal sexual acts that they had engaged in. Based on this assessment, dichotomous variables were created to classify participants in terms of those who engaged in condomless sex during the past 3 months versus those who did not; delineated by partner HIV serostatus.

\section{Statistical analysis}

The primary outcome focused on PrEP nonadherence as assessed through the ACTG-based measure described above. Statistical analysis first entailed a linear-by-linear test of association to assess whether increasing severity of alcohol use (i.e., AUDIT-based classification) was linked to a greater occurrence of PrEP nonadherence. Univariate logistic regression was then employed to assess the extent to which alcohol use, risky substance use, depression, and other factors of potential relevance to PrEP treatment (e.g., demographics, duration on PrEP, sexual partnerships) were associated with PrEP nonadherence. Factors significant at $p<.10$ in univariate analyses were included in a multivariate logistic regression model to identify independent predictors of PrEP nonadherence.

Alcohol-, substance use-, and depression-related factors that were found to be significant in the multivariate logistic regression model were further examined for possible syndemic production through tests of additive and interactive effects on PrEP nonadherence. A coding scheme was developed whereby the presence of a specific factor (e.g., hazardous/harmful drinking) was coded as " 1 ," and the absence coded as " 0 ." Accordingly, tests for possible additive effects entailed a logistic regression equation in which each participant's sum of factors was regressed on PrEP nonadherence. Tests for possible interactive, synergistic effects (e.g., determining whether the impact of alcohol plus moderate/high risk substance use on PrEP nonadherence exceeded the effects of the sum of the issues) followed procedures put forth by Tsai et al. [54, 55], and involved logistic regression modelling in which interaction terms between/among the factors were assessed in relation to PrEP nonadherence. Statistical analyses were conducted using SPSS version 24 [56].

\section{Results}

\section{Sample characteristics}

A total of 142 individuals consented to take part in the study. Data were excluded from one participant who did not complete the survey in its entirety, which yielded a sample of 141 for analysis. Sample characteristics can be found in Table 1. As shown in the table, mean age was 37.9 , and most participants identified their race as white (63.1\%) and sexual orientation as gay (92.9\%). High levels of employment, education, and income were evident among the sample. Fewer than half of participants (39.0\%) reported a current steady partnership, and the vast majority of the sample (93.6\%) reported the engagement in condomless sex during the past 3 months. Mean 
Table 1 Characteristics of study participants

\begin{tabular}{|c|c|}
\hline & $N=141$ \\
\hline Age: M (SD) & $37.9(10.6)$ \\
\hline \multicolumn{2}{|l|}{ Race/ethnicity n (\%) } \\
\hline White & 89 (63.1\%) \\
\hline Chinese & $14(9.9 \%)$ \\
\hline South Asian & $7(5.0 \%)$ \\
\hline Multi-race & $7(5.0 \%)$ \\
\hline Black & $5(3.5 \%)$ \\
\hline Arab & $5(3.5 \%)$ \\
\hline Latin American & $4(2.8 \%)$ \\
\hline Filipino & $3(2.1 \%)$ \\
\hline West Asian & $3(2.1 \%)$ \\
\hline Aboriginal & $2(1.4 \%)$ \\
\hline Southeast Asian & $1(0.7 \%)$ \\
\hline Japanese & $1(0.7 \%)$ \\
\hline \multicolumn{2}{|l|}{ Gender: n (\%) } \\
\hline Male & $139(98.6 \%)$ \\
\hline Non-binary & $2(1.4 \%)$ \\
\hline \multicolumn{2}{|l|}{ Sexual Orientation: n (\%) } \\
\hline Gay & $131(92.9 \%)$ \\
\hline Bisexual & $8(5.7 \%)$ \\
\hline Queer & $2(1.4 \%)$ \\
\hline Education = completed college/university: $\mathrm{n}(\%)$ & $114(80.9 \%)$ \\
\hline Employed full-time: n (\%) & $114(80.9 \%)$ \\
\hline Annual household income $\geq$ CAD \$100,000: n (\%) & $63(47.0 \%)$ \\
\hline Currently have a steady partner: $\mathrm{n}(\%)$ & $55(39.0 \%)$ \\
\hline \multicolumn{2}{|c|}{ Engaged in condomless sex during the past 3 months with ...: $n(\%)$} \\
\hline Any partner(s) & $132(93.6 \%)$ \\
\hline Any HIV-negative partner(s) & $109(79.6 \%)$ \\
\hline Any HIV status unknown partner(s) & $88(64.7 \%)$ \\
\hline Any HIV-positive partner(s) & $62(44.9 \%)$ \\
\hline Months on PrEP: M (SD) & $16.8(14.8)$ \\
\hline PrEP nonadherence - past 4 days: $\mathrm{n}(\%)$ & $28(19.9 \%)$ \\
\hline
\end{tabular}

Percentages are based on the number of participants who indicated a specific response divided by the number of participants who responded to the item CAD Canadian Dollar, PrEP Pre-Exposure Prophylaxis

duration on PrEP was 16.8 months, and one in five participants (19.9\%) reported missing at least one PrEP dose during the past 4 days.

\section{Alcohol, substance use, and depression}

As shown in Table 2, alcohol use was highly prevalent among the sample (drinkers $=92.9 \%$ ). One quarter (25.5\%) of all participants met AUDIT criteria for hazardous drinking, and an additional $6.4 \%$ of the sample met AUDIT criteria for harmful alcohol use. Substance use was also common, whereby $43.3 \%$ of participants were classified as moderate/high risk users of at least one substance. Approximately one quarter of the sample (23.7\%) met CESD-10 criteria for depression, and approximately one in five participants $(19.7 \%)$ reported receiving treatment for depression in the past 3 months.

\section{Predictors of PrEP nonadherence}

The linear-by-linear test of association for AUDIT-based classification was significant, demonstrating that increasing alcohol risk severity was associated with greater occurrence of PrEP nonadherence (i.e., low risk drinkers $=15.6 \%$ nonadherent; hazardous drinkers = $25.0 \%$ nonadherent; harmful drinkers $=44.4 \%$ nonadherent) $\left(\chi^{2}(1)=4.79, p=.029\right)$. Additionally, as shown in Table 3, univariate logistic regression analyses demonstrated that AUDIT-based classification, moderate/high risk cocaine use, and engaging in condomless sex with an HIV-positive partner during the past 3 months were associated with PrEP nonadherence. Associations between depression-related indicators and PrEP nonadherence were not significant. Inclusion of the three significant univariate factors in a multivariate logistic regression model demonstrated that AUDIT-based classification and moderate/high risk cocaine use remained as significant independent predictors, whereby harmful drinkers were over six times more likely to be nonadherent to PrEP than low risk drinkers $(\mathrm{AOR}=6.72,95 \% \mathrm{CI}=$ 1.49-30.33, $p=.013$ ), and moderate/high risk cocaine users were over three times more likely to be nonadherent than those without such risk $(\mathrm{AOR}=3.11,95 \% \mathrm{CI}=$ $1.01-9.59, p=.049)$.

\section{Tests for syndemic effects on PrEP nonadherence}

Based on findings from the multivariate logistic regression analysis, additive and interactive effects involving hazardous/harmful alcohol consumption and moderate/ high risk cocaine use in relation to PrEP nonadherence were examined. Among the sample of 141 PrEPprescribed gbMSM, 87 (61.7\%) reported neither hazardous/harmful drinking nor moderate/high risk cocaine use; 45 (31.9\%) reported one of these issues; and nine (6.4\%) reported both issues. As depicted in Fig. 1, the likelihood of PrEP nonadherence increased in conjunction with the number of issues one was experiencing. Accordingly, in support of an additive effect, logistic regression demonstrated that there was an approximately two-fold increase in the likelihood PrEP nonadherence for each additional issue that a participant was experiencing $(\mathrm{OR}=2.25, \quad 95 \% \mathrm{CI}=1.19-4.25, \quad p=.013)$. The interaction between hazardous/harmful drinking and moderate/high risk cocaine use was not significant $(\mathrm{OR}=0.77,95 \% \mathrm{CI}=.090-6.54, p=.809)$, suggesting that these two factors did not work in a synergistic, multiplicative manner in relation to PrEP nonadherence. 
Table 2 Alcohol, substance use, and depression among study participants

\begin{tabular}{|c|c|}
\hline & $N=141$ \\
\hline Alcohol consumption - any (AUDIT): n (\%) & $131(92.9 \%)$ \\
\hline \multicolumn{2}{|l|}{ Alcohol consumption - risk category (AUDIT): n (\%) } \\
\hline Low risk (score $0-7$ ) & $96(68.1 \%)$ \\
\hline Hazardous drinking (score 8-15) & $36(25.5 \%)$ \\
\hline Harmful drinking (score $\geq 16$ ) & $9(6.4 \%)$ \\
\hline \multicolumn{2}{|l|}{ Substance use - moderate/high risk (NIDA M-ASSIST): $\mathrm{n}(\%)$} \\
\hline Cannabis & $44(31.2 \%)$ \\
\hline Cocaine & $18(12.8 \%)$ \\
\hline Inhalants & $10(7.1 \%)$ \\
\hline Sedatives & $9(6.4 \%)$ \\
\hline Methamphetamines & $6(4.3 \%)$ \\
\hline Hallucinogens & $6(4.3 \%)$ \\
\hline Stimulants & $2(1.4 \%)$ \\
\hline Prescription opioids & $1(0.7 \%)$ \\
\hline Street opioids & $0(0.0 \%)$ \\
\hline Any substance & $61(43.3 \%)$ \\
\hline \multicolumn{2}{|l|}{ Depression-related indicators } \\
\hline Currently experiencing depression (CESD-10 score $\geq 10$ ): $n$ (\%) & $33(23.7 \%)$ \\
\hline Received treatment for depression - past 3 months: $\mathrm{n}(\%)$ & $25(19.7 \%)$ \\
\hline
\end{tabular}

Percentages are based on the number of participants who indicated a specific response divided by the number of participants who responded to the item AUDIT Alcohol Use Disorders Identification Test, NIDA M-ASSIST National Institute on Drug Abuse Modified Alcohol, Smoking and Substance Involvement Screening Test, CESD-10 Center for Epidemiologic Studies Depression 10-item scale

\section{Discussion}

One in five participants who had been prescribed daily PrEP for HIV prevention reported missing one or more of their PrEP doses over the past 4 days. Increasingly problematic levels of alcohol consumption among PrEPprescribed gbMSM were associated with a significantly increased likelihood of PrEP nonadherence, and this association was sustained when accounting for other relevant factors. Moderate/high risk cocaine use was also significantly linked to missing one's PrEP doses, but indicators related to depression were not. Finally, while problematic alcohol consumption and moderate/high risk cocaine use were shown to have independent and additive associations with PrEP nonadherence, evidence for a synergistic impact of the two risk factors on adherence was not yielded.

Findings pertaining to alcohol use and PrEP nonadherence accord with the broad literature on alcohol and adherence to ART $[29,31]$, and are consistent with the positive associations demonstrated among some investigations on PrEP adherence and problematic alcohol consumption [32, 34, 35]. In particular, our investigation demonstrated that participants with the most pronounced alcohol problems (i.e., harmful drinkers) were over six times more likely to be nonadherent to PrEP. Consuming alcohol at such problematic levels may substantially hinder one's motivation and/or ability to take PrEP as prescribed. It may also be the case that perceptions surrounding interactive toxicities between alcohol and PrEP result in conscious decisions to miss one's doses. Supportive evidence for such a connection has been demonstrated with respect to ART adherence [57], and recent PrEP-focused research suggests that this pattern may similarly exist for PrEP adherence as well [58]. Regardless of the potential mechanism, the demonstrated association between problematic alcohol use and PrEP nonadherence suggests that alcohol may comprise a considerable barrier to PrEP treatment.

Of note is that discrepancies between the current positive alcohol-related findings and the null associations yielded through some previous investigations (e.g., [36, 37]) may relate in part to the manner in which alcohol concerns were operationalized. Specifically, whereas many of these previous studies focused on "heavy drinking" which was typically defined as having a binge drinking episode, the present study employed AUDIT-based drinking criteria, which perhaps is better suited for more reliably identifying those with marked, persistent alcohol problems. Such problems, in turn, may be much more detrimental to PrEP-taking efforts than having an occasional, or even a single, binge drinking occurrence. 
Table 3 Associations with PrEP nonadherence in the past 4 days: Univariate and multivariate logistic regression

\begin{tabular}{|c|c|c|c|c|c|c|}
\hline \multirow[b]{3}{*}{ Factor } & \multicolumn{2}{|c|}{ PrEP Adherence - Past 4 Days } & \multirow[b]{3}{*}{ OR $(95 \% \mathrm{Cl})$} & \multirow[b]{3}{*}{$p$} & \multirow[b]{3}{*}{ AOR $(95 \% \mathrm{Cl})$} & \multirow[b]{3}{*}{$p$} \\
\hline & $\begin{array}{l}\text { Adherent }(n= \\
\text { 113) }\end{array}$ & $\begin{array}{l}\text { Nonadherent }(n= \\
\text { 28) }\end{array}$ & & & & \\
\hline & n (\%) & n (\%) & & & & \\
\hline Age $\geq 35$ & $65(57.5 \%)$ & $15(53.6 \%)$ & $\begin{array}{l}0.85(0.37- \\
1.96)\end{array}$ & .706 & & \\
\hline Race/Ethnicity = white & $73(64.6 \%)$ & $16(57.1 \%)$ & $\begin{array}{l}0.73(0.32- \\
1.70)\end{array}$ & .465 & & \\
\hline Education = completed college/university & $89(78.8 \%)$ & $25(89.3 \%)$ & $\begin{array}{l}2.25(0.63- \\
8.08)\end{array}$ & .215 & & \\
\hline Annual household income $\geq$ CAD $\$ 100,000$ & $51(47.2 \%)$ & $12(46.2 \%)$ & $\begin{array}{l}0.96(0.41- \\
2.26)\end{array}$ & .922 & & \\
\hline Employed full-time & $92(81.4 \%)$ & $22(78.6 \%)$ & $\begin{array}{l}0.84(0.30- \\
2.32)\end{array}$ & .732 & & \\
\hline Taking PrEP for $\geq 12$ months & $56(49.6 \%)$ & $15(53.6 \%)$ & $\begin{array}{l}1.17(0.51- \\
2.69)\end{array}$ & .704 & & \\
\hline Currently have a steady partner & $43(38.1 \%)$ & $12(42.9 \%)$ & $\begin{array}{l}1.22(0.53- \\
2.83)\end{array}$ & .641 & & \\
\hline $\begin{array}{l}\text { Condomless sex with any HIV-negative partners - past } 3 \\
\text { months }\end{array}$ & $90(81.8 \%)$ & $19(70.4 \%)$ & $\begin{array}{l}0.53(0.20- \\
1.38)\end{array}$ & .191 & & \\
\hline $\begin{array}{l}\text { Condomless sex with any HIV status unknown partners - past } \\
3 \text { months }\end{array}$ & $73(67.0 \%)$ & $15(55.6 \%)$ & $\begin{array}{l}0.62(0.26- \\
1.45)\end{array}$ & .269 & & \\
\hline Condomless sex with any HIV positive partners - past 3 months & $46(41.4 \%)$ & $16(59.3 \%)$ & $\begin{array}{l}2.06(0.87- \\
4.84)\end{array}$ & .099 & $\begin{array}{l}2.22(0.89- \\
5.56)\end{array}$ & .089 \\
\hline Alcohol Consumption (AUDIT) & & & & .096 & & .044 \\
\hline Low risk & $81(71.7 \%)$ & $15(53.6 \%)$ & Ref & & Ref & \\
\hline Hazardous & $27(23.9 \%)$ & $9(32.1 \%)$ & $\begin{array}{l}1.80(0.71- \\
4.58)\end{array}$ & .217 & $\begin{array}{l}1.54(0.57- \\
4.18)\end{array}$ & .399 \\
\hline Harmful & $5(4.4 \%)$ & $4(14.3 \%)$ & $\begin{array}{l}4.32(1.04- \\
17.97)\end{array}$ & .044 & $\begin{array}{l}6.72(1.49- \\
30.33)\end{array}$ & .013 \\
\hline Cannabis - moderate/high risk use (NIDA M-ASSIST) & $35(31.0 \%)$ & $9(32.1 \%)$ & $\begin{array}{l}1.06(0.44- \\
2.57)\end{array}$ & .905 & & \\
\hline Cocaine - moderate/high risk use (NIDA M-ASSIST) & $11(9.7 \%)$ & $7(25.0 \%)$ & $\begin{array}{l}3.09(1.07- \\
8.90)\end{array}$ & .037 & $\begin{array}{l}3.11(1.01- \\
9.59)\end{array}$ & .049 \\
\hline Inhalants - moderate/high risk use (NIDA MASSIST) & $6(5.3 \%)$ & $4(14.3 \%)$ & $\begin{array}{l}2.97(0.78- \\
11.36)\end{array}$ & .111 & & \\
\hline Sedatives - moderate/high risk use (NIDA MASSIST) & $6(5.3 \%)$ & $3(10.7 \%)$ & $\begin{array}{l}2.14(0.50- \\
9.15)\end{array}$ & .305 & & \\
\hline Any substance - moderate/high risk use (NIDA MASSIST) & $46(40.7 \%)$ & $15(53.6 \%)$ & $\begin{array}{l}1.68(0.73- \\
3.86)\end{array}$ & .221 & & \\
\hline Currently experiencing depression (CESD-10) & $25(22.5 \%)$ & $8(28.6 \%)$ & $\begin{array}{l}1.38(0.54- \\
3.50)\end{array}$ & .503 & & \\
\hline Received treatment for depression - past 3 months & $22(21.6 \%)$ & $3(12.0 \%)$ & $\begin{array}{l}0.50(0.14- \\
1.81)\end{array}$ & .289 & & \\
\hline
\end{tabular}

Percentages are based on the number of participants who indicated a specific response divided by the number of participants who responded to the item ORs could not be calculated for moderate/high risk methamphetamine, hallucinogen, stimulant, street opioid, and prescription opioid use due to empty cells AUDIT Alcohol Use Disorders Identification Test, NIDA M-ASSIST National Institute on Drug Abuse Modified Alcohol, Smoking and Substance Involvement Screening Test, CESD-10 Center for Epidemiologic Studies Depression 10-item scale

With respect to substances, consistent with previous research (e.g., [42]), moderate/high risk cocaine use was significantly associated with PrEP nonadherence. Consuming cocaine at elevated levels may be linked to impaired neurocognitive functioning and pronounced lifestyle disruptions [59]; both of which can diminish the likelihood of following one's PrEP regimen as prescribed. While this suggests that similar links between the risky use of other stimulants/club drugs (e.g., methamphetamines) and nonadherence should also have been yielded in our investigation [60], it is important to note that infrequent reports of moderate/high risk use of 


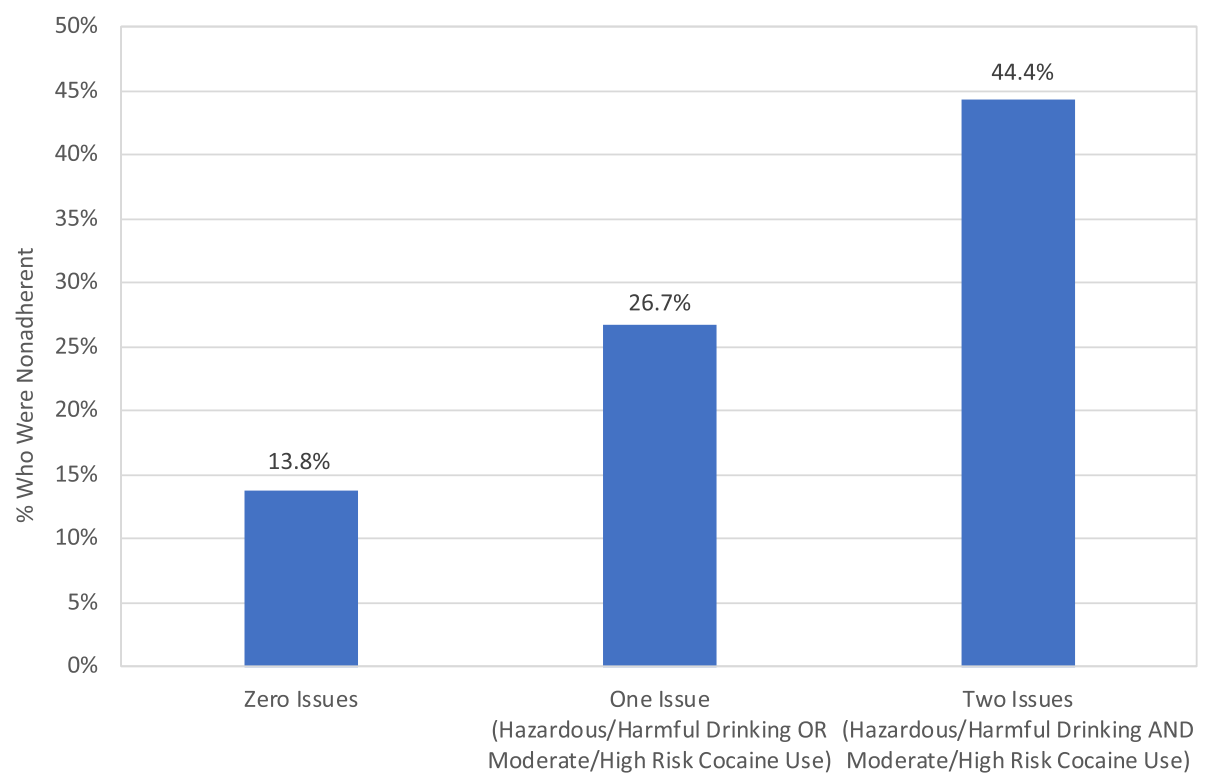

Fig. 1 Percent of participants who reported PrEP nonadherence among those with 1) neither hazardous/harmful drinking nor moderate/high risk cocaine use; 2) either hazardous/harmful drinking or moderate/high risk cocaine use; and 3) both hazardous/harmful drinking and moderate/high risk cocaine use

these other substances precluded us from being able to statistically evaluate these associations. Nevertheless, the strong association between cocaine and nonadherence highlights the challenge that substance use poses within the context of PrEP treatment.

Importantly, syndemic-focused analyses demonstrated a significant, progressively increasing likelihood of PrEP nonadherence in correspondence with the increased presence of problematic alcohol and cocaine use. Specifically, although the combined presence of problematic alcohol and cocaine use did not produce a synergistic association (possibly due to statistical power concerns see below), PrEP nonadherence was significantly most pronounced among those who were experiencing both issues. This additive pattern aligns with the ART adherence-focused literature on syndemics [46, 47], and it builds on this work by providing strong evidence for the dual burden of comorbid alcohol and substance use on PrEP treatment. Recognizing this pattern, and given the prevalence and concurrency of these issues among gbMSM in general $[39,40]$, it is clear that comorbid alcohol and other substance use require particular attention in PrEP-delivery settings.

Depression-related indicators were not found to be significantly related to PrEP nonadherence. Previous findings linking depression with PrEP adherence have been mixed [45, 61]; leading to the supposition that depression may not play a critical role in one's PrEP-taking behaviors [45]. Nevertheless, the noteworthy rate of depressive symptomatology reported by our PrEP- prescribed gbMSM suggests that efforts are necessary to identify and address depression among this population.

Taken together, findings from the present investigation have direct implications for PrEP treatment among gbMSM. Our work strongly suggests the need to integrate alcohol- and substance (i.e., cocaine)-focused initiatives into the context of PrEP clinical care. To start, screening for alcohol- and substance-related issues should occur not only during one's initial PrEP consultation, but also at each PrEP follow-up visit. Such a protocol would ensure that any alcohol and/or substance use issues that persist, develop, or recur over the course of one's PrEP treatment could be promptly identified. Subsequently, individuals who are recognized as possessing a marked issue regarding their alcohol and/or substance use could then be offered a wide-range of tailored, evidence-based interventions, which would help them achieve their harm-reduction goals, and in turn, could also potentially lead to improvements in PrEP adherence (see [62] for similar effects with respect to ART adherence). Alternatively, PrEP-focused adherence interventions could be offered to PrEP-prescribed gbMSM who possess alcohol- and/or substance-related issues. This targeted approach would be especially appealing in resource constrained settings, as focusing specifically on this particular subgroup that is most at risk for missing PrEP doses would help maximize financial and temporal efficiencies of adherence promotion efforts.

Findings should be viewed in terms of possible limitations. First, our PrEP nonadherence outcome was based 
on a self-report measure that focused on missing one or more doses over the course of a recent, relatively brief time period (i.e., the past 4 days). In general, self-report PrEP adherence measures have been shown to be subject to a greater degree of underreporting nonadherence compared to objective biomarker tests (e.g., [63-65]). Additionally, given that survey administration was temporally linked to one's clinic appointment, reports of PrEP adherence may have to some extent been impacted by a white coat compliance effect, whereby adherence to one's regimen tends to be higher in the days immediately preceding one's clinic visit [66]. The recency and brevity of our adherence assessment timeframe may therefore have produced adherence reports that may not have fully reflected longer term PrEP adherence patterns among the sample. Of additional relevance regarding our adherence measure was that nonadherence was defined as missing one or more PrEP dose over the past 4 days. This classification therefore included those who missed only one of four doses; reflecting an adherence rate of $75 \%$. Given that some evidence suggests that sufficient protection from HIV acquisition can be obtained at a PrEP adherence rate of $57 \%$ (i.e., four out of seven doses per week), our strict definition of nonadherence may possess a relatively lower degree of clinical consequence compared to approaches that employ more lenient adherence metrics.

Second, our assessments of alcohol consumption, substance use, and depression were based on self-report measures. More objective tests for alcohol and other substance use [67-69], along with a clinical diagnosis of depression, would more accurately identify these concerns. Third, data were cross-sectional in nature, and assessment timeframes varied across the validated measures (e.g., 4-day adherence, 3-month substance use). Employing longitudinal approaches and adapting the validated measures to follow consistent response timeframes (e.g., all based on 3 months) would help evaluate the temporal nature of the associations under investigation. Fourth, participants were recruited through convenience sampling at two clinic sites, and the resultant sample reflected a male, highly educated, and highincome population; all of whom had been taking PrEP for at least 3 months. As such, findings from the current investigation may not generalize to the broader PrEPprescribed population, including women; individuals from less affluent and less educated communities; and those with less established PrEP histories. Finally, the sample was relatively small, which may have resulted in diminished statistical power. This may have limited the ability not only to assess the associations between the moderate/high risk use of specific substances and PrEP nonadherence, but also to test for interactive syndemic effects. Future investigations involving larger samples would potentially be better positioned to evaluate these aspects.

\section{Conclusions}

The present findings underscore the marked role of problematic alcohol consumption and cocaine use in PrEP treatment. Identifying and addressing these issues within PrEP-delivery settings could enhance the effectiveness of PrEP, which in turn could lead to a reduction in HIV incidence among the broader population of gbMSM.

\section{Abbreviations}

ACTG: AIDS Clinical Trials Group; AOR: Adjusted Odds Ratio; ART: Antiretroviral therapy; AUDIT: Alcohol Use Disorders Identification Test; CESD-10: Center for Epidemiologic Studies Depression 10-item scale; gbMSM: Gay, bisexual and other men-who-have-sex-with-men; HIV: Human Immunodeficiency Virus; NIDA M-ASSIST: National Institute on Drug Abuse Modified Alcohol, Smoking and Substance Involvement Screening Test; OR: Odds Ratio; PrEP: Pre-Exposure Prophylaxis; RCT: Randomized controlled trial; TAF/FTC: Tenofovir alafenamide/emtricitabine; TDF/FTC: Tenofovir disoproxil fumarate/emtricitabine

\section{Acknowledgements}

We would like to thank study participants, research team members, and physicians and staff at the Maple Leaf Medical Clinic and Toronto General Hospital.

\section{Authors' contributions}

PAS, NJ, IB, ML, and JR contributed to the conception of the work. PAS, NJ, $\| B, M L, F C, P E, D C K$, and KW were involved in the acquisition of data. PAS, $\mathrm{NJ}$, and JR were involved in data analysis and interpretation. PAS, NJ, IIB, ML, and JR were involved in drafting the manuscript, and PAS, NJ, IIB, ML, FC, PE, $D C K, K W$, and JR were involved in the revision and finalization process. All authors have read and approved the manuscript.

\section{Funding}

Funding for this work was provided by the National Institute on Alcohol Abuse and Alcoholism (NIAAA)/National Institutes of Health (NIH) $(5 \mathrm{UH} 2$ AA026212-02, PI: Shuper). Dr. Shuper's salary is supported in part by The Ontario HIV Treatment Network (OHTN). The funders were not involved in study design, data collection, data analysis, data interpretation, or writing of the manuscript.

\section{Availability of data and materials}

The datasets generated during and/or analyzed during the current study are not publicly available due to research ethics-related requirements but may be available from the corresponding author on reasonable request.

\section{Ethics approval and consent to participate}

All participants provided written consent. Procedures were approved by Research Ethics Boards at the Center for Addiction and Mental Health

(Protocol\# 101-2018) and the University Health Network (Protocol\# 18-5014).

\section{Consent for publication}

Not applicable.

\section{Competing interests}

The authors declare that they have no competing interests.

\section{Author details}

${ }^{1}$ Institute for Mental Health Policy Research \& Campbell Family Mental Health Research Institute, Centre for Addiction and Mental Health (CAMH), 33 Russell St., Toronto, ON M5S 2S1, Canada. ${ }^{2}$ Dalla Lana School of Public Health, University of Toronto, 155 College St., Toronto, ON M5T 3M7, Canada. ${ }^{3}$ Divisions of General Internal Medicine and Infectious Diseases, University Health Network, 200 Elizabeth St., Toronto, ON M5G 2C4, Canada.

${ }^{4}$ Department of Medicine, University of Toronto, Medical Sciences Building, 1 
King's College Circle, Toronto, ON M5S 1A8, Canada. ${ }^{5}$ Women's College Hospital, 76 Grenville St., Toronto, ON M5S 1B2, Canada. ${ }^{6}$ Maple Leaf Medical Clinic, 14 College St., Toronto, ON M5G 1K2, Canada. ${ }^{7}$ Department of Medicine, Division of Infectious Diseases, McMaster University, 1200 Main St. W., Hamilton, ON L8N 3Z5, Canada. ${ }^{8}$ Department of Family and Community Medicine, University of Toronto, 500 University Ave., Toronto, ON M5G 1V7, Canada. ${ }^{9}$ Department of Psychiatry, University of Toronto, 250 College St., Toronto, ON M5T 1R8, Canada. ${ }^{10}$ PAHONHO Collaborating Centre for Addiction and Mental Health, 33 Russell St., Toronto, ON M5S 2S1, Canada.

${ }^{11}$ Epidemiological Research Unit, Technische Universität Dresden, Chemnitzer Str. 46, 01187 Dresden, Germany. ${ }^{12}$ Klinische Psychologie \& Psychotherapie, Chemnitzer Str. 46, 01187 Dresden, Germany. ${ }^{13}$ Department of International Health Projects, Institute for Leadership and Health Management, I.M. Sechenov First Moscow State Medical University, 8-2 Trubetskaya str., Moscow, Russian Federation 119991. ${ }^{14}$ Graduate Department of Community Health and Institute of Medical Science, University of Toronto, Medical Sciences Building, 1 King's College Circle, Toronto, ON M5S 1A8, Canada.

Received: 13 August 2020 Accepted: 12 November 2020

Published online: 25 November 2020

\section{References}

1. CATIE Canada's Source for HIV and Hepatitis C Information. Fact Sheet: The epidemiology of HIV in gay, bisexual and other men who have sex with men. 2018. https://www.catie.ca/sites/default/files/fs-epi-gbmsm-EN-201809-07.pdf Accessed 29 June 2020.

2. Centers for Disease Control and Prevention. HIV Surveillance Report, 2017, vol. 29; 2018. http://www.cdc.gov/hiv/library/reports/hiv-surveillance.html Accessed 24 Oct 2019

3. UNAIDS. Fact Sheet - Global AIDS Update 2019. https://www.unaids.org/ sites/default/files/media_asset/UNAIDS_FactSheet_en.pdf Accessed 24 Oct 2019.

4. Baeten JM, Donnell D, Ndase P, Mugo NR, Campbell JD, Wangisi J, Tappero JW, Bukusi EA, Cohen CR, Katabira E, et al. Antiretroviral prophylaxis for HIV prevention in heterosexual men and women. N Engl J Med. 2012;367(5): 399-410. https://doi.org/10.1056/NEJMoa1108524.

5. Grant RM, Lama JR, Anderson PL, McMahan V, Liu AY, Vargas L, Goicochea P, Casapia M, Guanira-Carranza JV, Ramirez-Cardich ME, et al. Preexposure chemoprophylaxis for HIV prevention in men who have sex with men. N Engl J Med. 2010;363(27):2587-99. https://doi.org/10.1056/NEJMoa1011205.

6. McCormack S, Dunn DT, Desai M, Dolling DI, Gafos M, Gilson R, Sullivan AK, Clarke A, Reeves I, Schembri G, et al. Pre-exposure prophylaxis to prevent the acquisition of HIV-1 infection (PROUD): effectiveness results from the pilot phase of a pragmatic open-label randomised trial. Lancet. 2016; 387(10013):53-60. https://doi.org/10.1016/50140-6736(15)00056-2.

7. Molina JM, Capitant C, Spire B, Pialoux G, Cotte L, Charreau I, Tremblay C, Le Gall JM, Cua E, Pasquet A, et al. On-demand preexposure prophylaxis in men at high risk for HIV-1 infection. N Engl J Med. 2015;373(23):2237-46. https://doi.org/10.1056/NEJMoa1506273.

8. Thigpen MC, Kebaabetswe PM, Paxton LA, Smith DK, Rose CE, Segolodi TM, Henderson FL, Pathank SR, Soud FA, Chillag KL, et al. Antiretroviral preexposure prophylaxis for heterosexual HIV transmission in Botswana. N Engl J Med. 2012;367(5):423-34. https://doi.org/10.1056/NEJMoa1110711.

9. Anderson PL, Glidden DV, Liu A, Buchbinder S, Lama JR, Guanira JV, McMahan V, Bushman LR, Casapia M, Montoya-Herrera O, et al. Emtricitabine-tenofovir concentrations and pre-exposure prophylaxis efficacy in men who have sex with men. Sci Transl Med. 2012;4(151): 151ra125. https://doi.org/10.1126/scitrans/med.3004006.

10. Volk JE, Marcus JL, Phengrasamy T, Blechinger D, Nguyen DP, Follansbee S, Hare CB. No new HIV infections with increasing use of HIV preexposure prophylaxis in a clinical practice setting. Clin Infect Dis. 2015;61(10):1601-3. https://doi.org/10.1093/cid/civ778.

11. Amico KR, Stirratt MJ. Adherence to preexposure prophylaxis: current, emerging, and anticipated bases of evidence. Clin Infect Dis. 2014;59(Suppl 1):S55-60. https://doi.org/10.1093/cid/ciu266

12. Grant RM, Anderson PL, McMahan V, Liu A, Amico KR, Mehrotra M, Hosek S, Mosquera C, Casapia M, Montoya O, et al. Uptake of pre-exposure prophylaxis, sexual practices, and HIV incidence in men and transgender women who have sex with men: a cohort study. Lancet Infect Dis. 2014; 14(9):820-9. https://doi.org/10.1016/S1473-3099(14)70847-3.
13. Marrazzo JM, Ramjee G, Richardson BA, Gomez K, Mgodi N, Nair G, Palanee T, Nakabiito C, van der Straten A, Noguchi L, et al. Tenofovir-based preexposure prophylaxis for HIV infection among African women. N Engl J Med. 2015;372(6):509-18. https://doi.org/10.1056/NEJMoa1402269.

14. Van Damme L, Corneli A, Ahmed K, Agot K, Lombaard J, Kapiga S, Malahleha M, Owino F, Manongi R, Onyango J, et al. Preexposure prophylaxis for HIV infection among African women. N Engl J Med. 2012; 367(5):411-22. https://doi.org/10.1056/NEJMoa1202614.

15. Molina JM, Charreau I, Spire B, Cotte L, Chas J, Capitant C, Tremblay C, Rojas-Castro D, Cua E, Pasquet A, et al. Efficacy, safety, and effect on sexual behaviour of on-demand pre-exposure prophylaxis for HIV in men who have sex with men: an observational cohort study. Lancet HIV. 2017;4(9): e402-10. https://doi.org/10.1016/S2352-3018(17)30089-9.

16. Closson EF, Mitty JA, Malone J, Mayer KH, Mimiaga MJ. Exploring strategies for PrEP adherence and dosing preferences in the context of sexualized recreational drug use among MSM: a qualitative study. AIDS Care. 2018; 30(2):191-8. https://doi.org/10.1080/09540121.2017.1360992.

17. Kibengo FM, Ruzagira E, Katende D, Bwanika AN, Bahemuka U, Haberer JE, Bangsberg DR, Barin B, Rooney JF, Mark D, et al. Safety, adherence and acceptability of intermittent tenofovir/emtricitabine as HIV pre-exposure prophylaxis (PrEP) among HIV-uninfected Ugandan volunteers living in HIVserodiscordant relationships: a randomized, clinical trial. PLoS One. 2013;8(9): e74314. https://doi.org/10.1371/journal.pone.0074314.

18. Mutua G, Sanders E, Mugo P, Anzala O, Haberer JE, Bangsberg D, Barin B, Rooney JF, Mark D, Chetty $P$, et al. Safety and adherence to intermittent pre-exposure prophylaxis (PrEP) for HIV-1 in African men who have sex with men and female sex workers. PLoS One. 2012;7(4):e33103. https://doi.org/10. 1371/journal.pone.0033103.

19. OHTN. Effectiveness of oral pre-exposure prophylaxis (PrEP) for HIV. 2018. http://www.ohtn.on.ca/wp-content/uploads/2018/10/RR129_PrEP_ Effectiveness.pdf Accessed 24 Oct 2019.

20. Centers for Disease Control and Prevention. Preexposure prophylaxis for the prevention of HIV infection in the United States. A Clinical Practice Guideline. 2014. https://www.cdc.gov/hiv/pdf/prepguidelines2014.pdf Accessed 13 Apr 2017

21. Tan DHS, Hull MW, Yoong D, Tremblay C, O'Byrne P, Thomas R, Kille J, Baril $J G$, Cox J, Giguere P, et al. Canadian guideline on HIV pre-exposure prophylaxis and nonoccupational postexposure prophylaxis. CMAJ. 2017; 189(47):E1448-58. https://doi.org/10.1503/cmaj.170494.

22. Lea T, Ryan D, Prestage G, Zablotska I, Mao L, de Wit J, Holt M. Alcohol use among a community-based sample of gay men: correlates of high-risk use and implications for service provision. Drug Alcohol Rev. 2015;34(4):349-57. https://doi.org/10.1111/dar.12234.

23. Ostrow DG, Stall R. Alcohol, tobacco, and drug use among gay and bisexual men. In: Wolitski RJ, Stall R, Valdiserri RO, editors. Unequal Opportunity: Health Disparities Affecting Gay and Bisexual Men in the United States. New York: Oxford University Press; 2008.

24. Vanable PA, McKirnan DJ, Buchbinder SP, Bartholow BN, Douglas JM Jr, Judson FN, MacQueen KM. Alcohol use and high-risk sexual behavior among men who have sex with men: the effects of consumption level and partner type. Health Psychol. 2004;23(5):525-32.

25. Woolf SE, Maisto SA. Alcohol use and risk of HIV infection among men who have sex with men. AIDS Behav. 2009;13(4):757-82. https://doi.org/10.1007/ s10461-007-9354-0.

26. Tan DHS, Leon-Carlyled M, Mills R, Moses E, Carvalhal A. Self-administered screening for syndemic mental health problems should be routinely implemented among MSM PrEP users. J Gay Lesbian Mental Health. 2016; 20(1):13-20.

27. De Boni RB, Machado IK, De Vasconcellos MTL, Hoagland B, Kallas EG, Madruga JV, Fernandes NM, Cerqueira NB, Moreira Rl, Goulart SP, et al. Syndemics among individuals enrolled in the PrEP Brasil study. Drug Alcohol Depend. 2018;185:168-72. https://doi.org/10.1016/j.drugalcdep.2017. 12.016.

28. Braithwaite RS, Conigliaro J, McGinnis KA, Maisto SA, Bryant K, Justice AC. Adjusting alcohol quantity for mean consumption and intoxication threshold improves prediction of nonadherence in HIV patients and HIV-negative controls. Alcohol Clin Exp Res. 2008;32(9):1645-51.

29. Hendershot CS, Stoner SA, Pantalone DW, Simoni JM. Alcohol use and antiretroviral adherence: review and meta-analysis. J Acquir Immune Defic Syndr. 2009;52(2):180-202. https://doi.org/10.1097/QAl.0b013e3181b18b6e. 
30. Grodensky CA, Golin CE, Ochtera RD, Turner BJ. Systematic review: effect of alcohol intake on adherence to outpatient medication regimens for chronic diseases. J Stud Alcohol Drugs. 2012;73(6):899-910.

31. Parsons JT, Rosof E, Mustanski B. The temporal relationship between alcohol consumption and HIV-medication adherence: a multilevel model of direct and moderating effects. Health Psychol. 2008;27(5):628-37.

32. Haberer JE, Baeten JM, Campbell J, Wangisi J, Katabira E, Ronald A, Tumwesigye E, Psaros C, Safren SA, Ware NC, et al. Adherence to antiretroviral prophylaxis for HIV prevention: a substudy cohort within a clinical trial of serodiscordant couples in East Africa. PLoS Med. 2013;10(9): e1001511. https://doi.org/10.1371/journal.pmed.1001511.

33. Cherpitel CJ, Ye Y, Bond J, Rehm J, Poznyak V, MacDonald S, Stafstrom M, Hao W. Multi-level analysis of alcohol-related injury among emergency department patients: a cross-national study. Addiction. 2005;100(12):184050 .

34. Mugo PM, Sanders EJ, Mutua G, van der Elst E, Anzala O, Barin B, Bangsberg $\mathrm{DR}$, Priddy $\mathrm{FH}$, Haberer JE. Understanding adherence to daily and intermittent regimens of oral HIV pre-exposure prophylaxis among men who have sex with men in Kenya. AIDS Behav. 2015;19(5):794-801. https:// doi.org/10.1007/s10461-014-0958-X.

35. van der Elst EM, Mbogua J, Operario D, Mutua G, Kuo C, Mugo P, Kanungi J, Singh S, Haberer J, Priddy F, et al. High acceptability of HIV pre-exposure prophylaxis but challenges in adherence and use: qualitative insights from a phase I trial of intermittent and daily PrEP in at-risk populations in Kenya. AIDS Behav. 2013;17(6):2162-72. https://doi.org/10.1007/s10461-012-0317-8.

36. Grov C, Rendina HJ, John SA, Parsons JT. Determining the roles that club drugs, marijuana, and heavy drinking play in PrEP medication adherence among gay and bisexual men: implications for treatment and research. AIDS Behav. 2019;23(5):1277-86. https://doi.org/10.1007/ s10461-018-2309-9.

37. Hojilla JC, Vlahov D, Glidden DV, Amico KR, Mehrotra M, Hance R, Grant RM, Carrico AW. Skating on thin ice: stimulant use and sub-optimal adherence to HIV pre-exposure prophylaxis. J Int AIDS Soc. 2018;21(3):e25103. https:// doi.org/10.1002/jia2.25103.

38. Velloza J, Bacchetti P, Hendrix CW, Murnane P, Hughes JP, Li M, Curlin ME, Holtz TH, Mannheimer S, Marzinke MA, et al. Short- and long-term pharmacologic measures of HIV pre-exposure prophylaxis use among highrisk men who have sex with men in HPTN 067/ADAPT. J Acquir Immune Defic Syndr. 2019;82(2):149-58. https://doi.org/10.1097/QAl. 0000000000002128.

39. Marshall BD, Operario D, Bryant KJ, Cook RL, Edelman EJ, Gaither JR, Gordon AJ, Kahler CW, Maisto SA, McGinnis KA, et al. Drinking trajectories among HIV-infected men who have sex with men: a cohort study of United States veterans. Drug Alcohol Depend. 2015;148:69-76. https://doi.org/10.1016/j. drugalcdep.2014.12.023.

40. Marshall BD, Shoveller JA, Kahler CW, Koblin BA, Mayer KH, Mimiaga MJ, van den Berg JJ, Zaller ND, Operario D. Heavy drinking trajectories among men who have sex with men: a longitudinal, group-based analysis. Alcohol Clin Exp Res. 2015;39(2):380-9. https://doi.org/10.1111/acer.12631.

41. Hoenigl M, Jain S, Moore D, Collins D, Sun X, Anderson PL, Corado K, Blumenthal JS, Daar ES, Milam J, et al. Substance use and adherence to HIV Preexposure Prophylaxis for men who have sex with men (1). Emerg Infect Dis. 2018;24(12). https://doi.org/10.3201/eid2412.180400.

42. Hojilla JC, Satre DD, Glidden DV, McMahan VM, Gandhi M, Defechereux P, Guanira JV, Mehrotra M, Grant RM, Carrico AW. Brief report: cocaine use and pre-exposure prophylaxis: adherence, care engagement, and kidney function. J Acquir Immune Defic Syndr. 2019;81(1):78-82. https://doi.org/10. 1097/QAI.0000000000001972.

43. Holtz TH, Chitwarakorn A, Hughes JP, Curlin ME, Varangrat A, Li M, Amico KR, Mock PA, Grant RM. HPTN 067/ADAPT: correlates of sex-related preexposure prophylaxis adherence, Thai men who have sex with men, and transgender women, 2012-2013. J Acquir Immune Defic Syndr. 2019;82(2): e18-26. https://doi.org/10.1097/QAl.0000000000002131.

44. Pasipanodya EC, Jain S, Sun X, Blumenthal J, Ellorin E, Corado K, Dube MP, Daar ES, Morris SR, Moore DJ. Trajectories and predictors of longitudinal preexposure prophylaxis adherence among men who have sex with men. J Infect Dis. 2018;218(10):1551-9. https://doi.org/10.1093/infdis/jiy368.

45. Mehrotra ML, Glidden DV, McMahan V, Amico KR, Hosek S, Defechereux P, Mayer KH, Veloso VG, Bekker LG, Avelino-Silva VI, et al. The effect of depressive symptoms on adherence to daily Oral PrEP in men who have sex with men and transgender women: a marginal structural model analysis of the iPrEx OLE study. AIDS Behav. 2016;20(7):1527-34. https://doi.org/10, 1007/s10461-016-1415-9.

46. Friedman MR, Stall R, Silvestre AJ, Wei C, Shoptaw S, Herrick A, Surkan PJ, Teplin L, Plankey MW. Effects of syndemics on HIV viral load and medication adherence in the multicentre AIDS cohort study. AIDS. 2015;29(9):1087-96. https://doi.org/10.1097/QAD.0000000000000657.

47. Kuhns LM, Hotton AL, Garofalo R, Muldoon AL, Jaffe $K$, Bouris A, Voisin D, Schneider J. An index of multiple psychosocial, syndemic conditions is associated with antiretroviral medication adherence among HIV-positive youth. AIDS Patient Care STDs. 2016;30(4):185-92. https://doi.org/10.1089/ apc.2015.0328.

48. Qualtrics. Released 2005. Qualtrics software, Version 13.018. Provo, UT, USA.

49. Chesney MA, Ickovics JR, Chambers DB, Gifford AL, Neidig J, Zwickl B, Wu AW. Self-reported adherence to antiretroviral medications among participants in HIV clinical trials: the AACTG adherence instruments. Patient Care Committee \& Adherence Working Group of the outcomes Committee of the Adult AIDS Clinical Trials Group (AACTG). AIDS Care. 2000;12(3):25566. https://doi.org/10.1080/09540120050042891.

50. Babor TF, Higgins-Biddle JC, Saunders JB, Monteiro MG. Dependence WHODoMHaS: the alcohol use disorders identification test. Guidelines for use in primary care. 2nd ed. Geneva: World Health Organization; 2001.

51. National Institute on Drug Abuse. Resource guide: screening for drug use in general medical settings. 2012. https://www.drugabuse.gov/publications/ resource-guide Accessed 13 Apr 2017.

52. Andresen EM, Malmgren JA, Carter WB, Patrick DL. Screening for depression in well older adults: evaluation of a short form of the CES-D (Center for Epidemiologic Studies Depression Scale). Am J Prev Med. 1994;10(2):77-84.

53. The Explore Team. Effects of a behavioural intervention to reduce acquisition of HIV infection among men who have sex with men: the EXPLORE randomised controlled study. Lancet. 2004;364:41-50. https://doi. org/10.1016/S0140-6736(04)16588-4.

54. Tsai AC, Burns BF. Syndemics of psychosocial problems and HIV risk: a systematic review of empirical tests of the disease interaction concept. Soc Sci Med. 2015;139:26-35. https://doi.org/10.1016/j.socscimed.2015.06.024.

55. Tsai AC, Venkataramani AS. Syndemics and health disparities: a methodological note. AIDS Behav. 2016;20(2):423-30. https://doi.org/10. 1007/s10461-015-1260-2.

56. IBM Corp. Released 2016. IBM SPSS Statistics for Windows, Version 24.0. Armonk, NY, USA.

57. Kalichman SC, Amaral CM, White D, Swetsze C, Pope H, Kalichman MO, Cherry C, Eaton L. Prevalence and clinical implications of interactive toxicity beliefs regarding mixing alcohol and antiretroviral therapies among people living with HIV/AIDS. AIDS Patient Care STDs. 2009;23(6):449-54.

58. Kalichman SC, Eaton L. Alcohol-antiretroviral interactive toxicity beliefs as a potential barrier to HIV pre-exposure prophylaxis among men who have sex with men. J Int AIDS Soc. 2017;20(1):1-8. https://doi.org/10.7448/IAS.20.1. 21534.

59. Hinkin CH, Barclay TR, Castellon SA, Levine AJ, Durvasula RS, Marion SD, Myers HF, Longshore D. Drug use and medication adherence among HIV-1 infected individuals. AIDS Behav. 2007;11(2):185-94. https://doi.org/10.1007/ s10461-006-9152-0.

60. Moore DJ, Blackstone K, Woods SP, Ellis RJ, Atkinson JH, Heaton RK, Grant I. Methamphetamine use and neuropsychiatric factors are associated with antiretroviral non-adherence. AIDS Care. 2012;24(12):1504-13.

61. Velloza J, Baeten JM, Haberer J, Ngure K, Irungu E, Mugo NR, Celum C, Heffron R. Effect of depression on adherence to oral PrEP among men and women in East Africa. J Acquir Immune Defic Syndr. 2018;79(3):330-8. https://doi.org/10.1097/QAl.0000000000001821.

62. Scott-Sheldon LA, Walstrom P, Carey KB, Johnson BT, Carey MP. Alcohol use and sexual risk behaviors among individuals infected with HIV: a systematic review and meta-analysis 2012 to early 2013. Curr HIV/AIDS Rep. 2013;10(4): 314-23. https://doi.org/10.1007/s11904-013-0177-5.

63. Abaasa A, Hendrix C, Gandhi M, Anderson P, Kamali A, Kibengo F, Sanders EJ, Mutua G, Bumpus NN, Priddy F, et al. Utility of different adherence measures for PrEP: patterns and incremental value. AIDS Behav. 2018;22(4): 1165-73. https://doi.org/10.1007/s10461-017-1951-y.

64. Agot K, Taylor D, Corneli AL, Wang M, Ambia J, Kashuba AD, Parker C, Lemons A, Malahleha M, Lombaard J, et al. Accuracy of self-report and pillcount measures of adherence in the FEM-PrEP clinical trial: implications for future HIV-prevention trials. AIDS Behav. 2015;19(5):743-51. https://doi.org/ 10.1007/s10461-014-0859-Z. 
65. Musinguzi N, Muganzi CD, Boum Y, Ronald A, Marzinke MA, Hendrix CW, Celum C, Baeten JM, Bangsberg DR, Haberer JE. Comparison of subjective and objective adherence measures for preexposure prophylaxis against HIV infection among serodiscordant couples in East Africa. AIDS. 2016;30(7): 1121-9. https://doi.org/10.1097/QAD.0000000000001024.

66. Podsadecki TJ, Vrijens BC, Tousset EP, Rode RA, Hanna GJ. "White coat compliance" limits the reliability of therapeutic drug monitoring in HIV-1infected patients. HIV Clin Trials. 2008;9(4):238-46. https://doi.org/10.1310/ hct0904-238.

67. Bajunirwe F, Haberer JE, Boum Y, Hunt P, Mocello R, Martin JN, Bangsberg $D R$, Hahn JA. Comparison of self-reported alcohol consumption to phosphatidylethanol measurement among HIV-infected patients initiating antiretroviral treatment in southwestern Uganda. PLoS One. 2014;9(12): e113152. https://doi.org/10.1371/journal.pone.0113152.

68. DuPont RL, Baumgartner WA. Drug testing by urine and hair analysis: complementary features and scientific issues. Forensic Sci Int. 1995;70(1-3): 63-76. https://doi.org/10.1016/0379-0738(94)01625-f.

69. Thakarar K, Asiimwe SB, Cheng DM, Forman L, Ngabirano C, Muyindike WR Emenyonu NI, Samet JH, Hahn JA. Alcohol consumption in Ugandan HIVinfected household-brewers versus non-brewers. AIDS Behav. 2016;20(10): 2408-17. https://doi.org/10.1007/s10461-016-1421-y.

\section{Publisher's Note}

Springer Nature remains neutral with regard to jurisdictional claims in published maps and institutional affiliations.

Ready to submit your research? Choose BMC and benefit from:

- fast, convenient online submission

- thorough peer review by experienced researchers in your field

- rapid publication on acceptance

- support for research data, including large and complex data types

- gold Open Access which fosters wider collaboration and increased citations

- maximum visibility for your research: over $100 \mathrm{M}$ website views per year

At BMC, research is always in progress.

Learn more biomedcentral.com/submissions 